\title{
La pena de muerte: situación actual desde una perspectiva internacional*
}

\author{
Death penalty: current situation, from an international perspective
}

\begin{abstract}
Lidia Valiente Castellanos**
*Trabajo clasificado c omo artículo de resultado de investigación. Desarrollado en el marco de la investigación de postgrado de la Universidad de Castilla - La Mancha, España

**Graduada en Derecho Universidad de Castilla, La Mancha, España
\end{abstract}

Fecha de recepción: Mayo de 2019

Fecha de aprobación: julio de 2019

Para citar este artículo / To reference this article Valiente, L. (2019) La pena de muerte. Situación actual desde una perspectiva internacional. Inciso, 21;84-102.

DOI: http://dx.doi.org/10.18634/incj.21v.1i.913

\section{Resumen}

La presente investigación se centra en la situación actual de la pena de muerte a nivel global. Para ello, se estudian los diferentes tratamientos que se dan por parte de los Estados a esta sanción, así como los Estados que practican cada uno de ellos. En primer lugar, se realiza una aproximación al uso actual de la pena de muerte en el mundo para conocer en qué países se utiliza y está vigente, y en cuáles no; y en segundo lugar, se estudia el marco jurídico internacional que determina la aplicación de esta pena, el cual ha sido elaborado fundamentalmente en el seno de organismos internacionales como la Organización de las Naciones Unidas. Desde el punto de vista metodológico, se han utilizado fuentes rigurosamente actualizadas y especializadas en la materia. Tras la realización de esta investigación se ha hallado una gran diversidad de situaciones en las que se encuentra la aplicación de esta sanción, así como los distintos instrumentos jurídicos, de carácter fundamentalmente internacional, utilizados para regularla, de allí que se pueda concluir: por una parte, la tendencia imperante actualmente en el mundo de abolir de la pena de muerte; y por otra, la posición de algunos Estados retencionistas en mantener esta sanción como una pena vigente, la cual en su aplicación es efectiva y al parecer está lejos de lograr su abolición.

Palabras clave: Ley, Estado, pena de muerte, régimen jurídico, derechos de los prisioneros, derechos humanos. 


\section{Abstract}

The present investigation focuses on the current situation of death penalty, at global level. For this, the different treatments that are given by the States to this sanction are studied, as well as the States that practice each of them. First, an approximation is made to the current use of death penalty in the world, in order to know in which countries it is used and is in force, and in which countries it is not. Second, it is studied the international legal framework that determines the application of this penalty, which has been elaborated fundamentally within international organizations, such as the United Nations Organization. From a methodological point of view, rigorously updated and specialized sources in the field have been used. After conducting this investigation, there have been found a great diversity of situations, in which it is found the application of this sanction, as well as the different legal instruments, fundamentally of international character, used to regulate it. Hence, it can be concluded: on the one hand, the current trend in the world to abolish death penalty; and on the other hand, the position of some retention states in maintaining this sanction as a valid penalty, which in its application is effective and apparently is far from being abolished.

Keywords: Law, State, death penalty, legal regime, rights of prisoners, human rights.

\section{INTRODUCCIÓN}

La pena de muerte es una sanción penal que supone la privación definitiva de la vida, el bien jurídico más fundamental para el ser humano, así como la violación de otro conjunto de derechos fundamentales. Esto, unido a la todavía incidencia de esta sanción en un amplio grupo de ordenamientos jurídicos justifica la realización de este estudio. \}

Por otro lado, no se debe obviar que la utilización de la pena de muerte es una cuestión tradicionalmente polémica, y de hecho, en la actualidad no se ha logrado alcanzar un acuerdo global sobre este asunto. Numerosos organismos internacionales con relevancia y reconocimiento global, se han implicado en esta cuestión y han regulado ampliamente sobre el tema, no obstante, la cuestión desde hace tiempo ha dado lugar a un profundo debate internacional que actualmente todavía continúa abierto y parece lejos de resolverse puesto que, como se verá a lo largo de este ensayo, dentro del debate sobre la utilización de la pena de muerte se pueden encontrar posturas radicalmente opuestas. En algún momento de su historia, ya sea por razones de tipo religioso, político o legal, todos los Estados han debido tomar una decisión respecto a la aplicación o abolición de la pena capital y desde los primeros debates sobre la abolición de la pena de muerte, los movimientos abolicionistas que acogen algunos Estados, por lo general, son lentos y graduales. Es decir, los Estados que emprenden el camino hacia la abolición de la pena de muerte experimentan una sucesión en varias etapas que dan lugar a las diversas situaciones que se encuentran en el mundo respecto a la aplicación de la pena capital.

Todas estas cuestiones serán puntualmente abordadas en los dos apartados que articulan el ensayo. Concretamente, en un primer apartado se analizarán los distintos sistemas posibles que existen en el tratamiento de la pena de muerte junto con los Estados que aplican cada sistema. Posteriormente, se estudiará la regulación internacional más relevante que contempla esta materia, junto con los problemas interpretativos que han suscitado parte de sus disposiciones. 


\section{UNa APROXIMAción A La PENA de MUERTE EN EL MUNDO}

A lo largo de este punto se van a desarrollar los diferentes sistemas posibles que existen en el tratamiento de la pena de muerte, las características concretas de cada uno de estos sistemas y los Estados que aplican cada sistema ( Hood \& Hoyle, 2017).

\section{a) Estados retencionistas}

Actualmente 40 Estados son considerados activamente retencionistas. Este grupo está formado por los países que mantienen la pena capital como una sanción penal, y la aplican activa y legalmente de acuerdo con su derecho interno, por tanto, llevan a cabo la mayor parte de las ejecuciones por penas de muerte que se practican en el mundo. Los Estados retencionistas se concentran en zonas geográficas muy concretas situadas fundamentalmente en Oriente Medio, Asia, África y Norteamérica. Pero también se encuentran otros Estados aislados, situados fuera de estas regiones, en los que se aplica la pena de muerte ${ }^{1}$.

Debemos destacar que entre los Estados que se encuentran en este grupo existen grandes diferencias en la aplicación de la pena de muerte, aunque la tendencia global legislativa imperante es la de no imponer la pena capital de manera absoluta (Barbero, Santos, 2013). Por un lado, se encuentran regiones como Oriente Medio y África, zonas muy afectadas por la pena de muerte debido fundamentalmente a la inestabilidad política que existe y al hecho innegable de que en varios de estos países la "ley civil" es la misma "ley religiosa". Siria se encuentra en la situación más grave con una compleja guerra civil que no parece finalizar todavía y actualmente millones de sirios huyen del país para buscar asilo en otras partes del mundo como refugiados. Por otro lado, podemos encontrar Estados como Corea del Norte o China, donde existe estabilidad política pero con regímenes autoritarios fuertemente implantados que ostentan el mayor número de ejecuciones, y aunque la cifra exacta no puede conocerse, ya que en ambos casos se trata de un secreto de Estado, sabemos algunas particularidades gracias a NNUU (Unidas \& Naciones Unidas , 2013) ${ }^{2}$.

En Corea del Norte la pena de muerte se aplica en gran medida, convive con otras violaciones de los derechos humanos que afectan a la población norcoreana de manera sistemática y generalizada, y de hecho, se estima que desde 1948 se han producido alrededor de 3.000 ejecuciones estando la mayoría de ellas asociadas a condenas por razones políticas o delitos menores $^{3}$. No obstante, China es el país más preocupante pues sabemos que las ejecuciones en esta región son muy superiores a las del resto de Estados retencionistas en su conjunto, de hecho, la República Popular de China ha practicado el 95\% de las ejecuciones judiciales en el mundo durante bastante tiempo. Estamos hablando del mayor ejecutor conocido actualmente y esto se debe, en gran medida, al número tan amplio de delitos que se castigan con la pena de muerte, y las diversas categorías delictivas en las que se encuadran estos delitos capitales ${ }^{4}$.

\footnotetext{
cfr., a Bielorrusia como una ciudad situada en Europa, la cual aún es considerada como una región abolicionista por excelencia y a su vez es un Estado retencionista que aplica efectiva y legalmente la pena de muerte dentro de su territorio y de acuerdo a su derecho interno.

2. cfr., NNUU ha creado ad hoc varias ONG en la zona como la Comisión de Investigación de los Derechos Humanos en Corea del Norte, creada por el Consejo de NNUU en marzo de 2013; o el Centro de Información para los Derechos Humanos en Corea del Norte (NKDB), ONG con sede en Corea del Sur.

3. cfr., En Corea del Norte se castiga con la pena de muerte delitos como la huida a China, la visualización de vídeos prohibidos de Corea del Sur, o la celebración de fiestas en los periodos de luto oficial. Además, las ejecuciones se realizan de manera pública y se obliga a los familiares de los presos a estar presentes en el acto.

4. cfr., 55 delitos son castigados con la pena de muerte en China y pertenecen a distintas categorías delictivas como por ejemplo: delitos de drogas y sus derivados, delitos de carácter económico y patrimonial como los delitos de "cuello blanco".
} 
Finalmente, dentro del grupo de Estados retencionistas encontramos países como los Estados Unidos de América (EEUU), en los que la aplicación de la pena de muerte no se realiza de manera tan masiva ni indiscriminada como en los casos anteriores, sino que en estos Estados las ejecuciones se practican por unos delitos concretos considerados "muy graves", con finalidades utilitaristas diferentes a la retribución en sí misma y tras un proceso judicial en el que, en principio, se respetan las garantías internacionalmente establecidas.

\section{b) Estados abolicionistas}

Los países abolicionistas se concentran fundamentalmente en las regiones de Europa oriental y occidental, Oceanía, los Estados de la Antigua Unión Soviética y América Latina (Amnistía Internacional, 1995). La historia inequívocamente nos muestra que estos países en el pasado eran retencioncitas, por lo tanto, aplicaban legalmente la pena de muerte. Sin embargo, ahora entran dentro del apartado de Estados abolicionistas porque han decidido separarse de este castigo y restringir su aplicación.

Este cambio de postura no es automático sino gradual, por lo tanto, los países abolicionistas suelen comenzar estableciendo una moratoria, periodo en el que no se producen ejecuciones por disposición del Gobierno Estatal, (así de facto, dejan de aplicar la pena de muerte aunque de iure pueden hacerlo), esta moratoria es seguida por una restricción legal de los delitos castigados con la pena capital, hasta que la misma se prohíbe para todos los delitos comunes u ordinarios perpetrados en tiempos de paz, finalmente, el proceso abolicionista culmina con la prohibición legal de aplicar la pena de muerte para cualquier delito y en cualquier circunstancia.

\section{c) Estados abolicionistas de facto}

Actualmente, se encuentran 48 Estados abolicionistas de facto en todo el mundo ( Amnistia Internacional,, 2015- 2016). La mayoría se encuentran en el continente africano ${ }^{5}$, otros pertenecen al Caribe ${ }^{6}$, algunos forman parte de los continentes de Asia ${ }^{7}$ u Oceanía ${ }^{8}$, y también hay países abolicionistas de facto en las regiones de América ${ }^{9}$ y Oriente Medio ${ }^{10}$.

Los Estados abolicionistas de facto han dado el primer paso para abandonar la pena de muerte, son denominados de esta manera, porque "de hecho" no aplican la pena capital, aunque "por ley" pueden hacerlo, ya que al igual que los Estados retencionistas mantienen la pena de muerte vigente en sus legislaciones como una sanción penal aplicable por su jurisdicción ordinaria a los culpables de delitos comunes. Sin embargo, han emprendido el camino de la abolición y se encuentran dentro de este grupo porque, aunque pueden continuar emitiendo sentencias de muerte no ejecutan las condenas capitales que se dictan.

\footnotetext{
5 .cfr., Estados abolicionistas de facto en África, ordenados cronológicamente de acuerdo a la fecha de la última ejecución: Níger, Mali, República Centro Africana, Suazilandia, Kenia, Burkina Faso, Eritrea, Mauritania, Túnez, Malawi, Argelia, Ghana, Marruecos, Tanzania, Lesoto, Camerún, Comoras, Zambia, Sierra Leona, Liberia, Guinea y la República Democrática del Congo

6. cfr., Estados abolicionistas de facto en el Caribe, ordenados cronológicamente de acuerdo a la fecha de la última ejecución: Granada, Barbados, Dominica, Jamaica, Antigua y Barbuda, San Vicente y las Granadinas, Santa Lucía, Trinidad y Tobago, Bahamas y Cuba.

7. cfr., Estados abolicionistas de facto en Asia, ordenados cronológicamente de acuerdo a la fecha de la última ejecución: Maldivas, Brunei, Sri Lanka, Laos, Myanmar, Rusia, Corea del Sur y Tayikistán.

8. cfr., Estados abolicionistas de facto en Oceanía, ordenados cronológicamente de acuerdo a la fecha de la última ejecución: Papúa Nueva Guinea, Nauru y Tonga.

9. cfr., Estados abolicionistas de facto en América, ordenados cronológicamente de acuerdo a la fecha de la última ejecución: Belice, Guayana y Guatemala.

10.cfr., Estados abolicionistas de facto en Oriente Medio, ordenados cronológicamente de acuerdo a la fecha de la última ejecución: Qatar y el Líbano.
} 
Para que los Estados sean considerados abolicionistas de facto deben llevar al menos 10 años sin realizar ejecuciones, o se les puede considerar inmediatamente abolicionistas de facto si el Gobierno del país establece oficialmente una moratoria. No obstante, estos países no se han comprometido a no reanudar los ajusticiamientos, ya que mientras la abolición de iure supone una suspensión definitiva de las ejecuciones, la abolición de facto no lo garantiza. La moratoria que establece el Gobierno es provisional, depende de la voluntad de responsables políticos como el Presidente del Gobierno o el Ministro de Justicia. De hecho, países que llevan más de 10 años sin aplicar la pena de muerte, en cualquier momento pueden ejecutar a un condenado y convertirse nuevamente en Estados retencionistas.

\section{d) Estados abolicionistas de iure}

Los Estados abolicionistas de iure son aquellos que legalmente han prohibido la aplicación de la pena de muerte (Gallego, 2005). Es decir, en estos países no existe la pena capital en los códigos penales ordinarios. No obstante, podemos hacer dos distinciones dentro de los Estados abolicionistas de iure:

\section{e) Estados parcialmente abolicionistas}

Actualmente 7 Estados de distintas regiones del mundo se encuentran en esta situación ${ }^{11}$. Los Estados de este grupo han abolido la pena de muerte de sus códigos penales para todos los delitos comunes en tiempos de paz, pero mantienen algunas excepciones que permiten aplicar la pena capital en ocasiones excepcionales.

Se puede decir que el sistema característico de estos Estados es, por tanto, una abolición de iure; porque se prohíbe legalmente la aplicación de la pena capital, pero al mismo tiempo es una abolición parcial; porque se mantiene la posibilidad de aplicarla en contextos y circunstancias excepcionales, por ejemplo, contra delitos militares en tiempos de guerra o contra ataques terroristas, ya que como dijo ANCEL; “Incluso los más convencidos abolicionistas se dieron cuenta de que pueden ocurrir circunstancias especiales o tiempos especialmente problemáticos que justifican la introducción de la pena de muerte por un periodo limitado".

\section{f) Estados totalmente abolicionistas}

Actualmente en el mundo existen 102 países totalmente abolicionistas de iure ${ }^{12}$ ( Amnistia Internacional,, 2015- 2016). En este apartado se encuentran los Estados que legalmente han suprimido la pena de muerte de sus Códigos Penales ordinarios y militares, para todos los delitos y en todas las circunstancias, sin excepción. Han llegado al final del proceso abolicionista. No pueden aplicar la pena capital y son la contraposición a los Estados retencionistas.

Este grupo está formado por países de diversas regiones del mundo, en primer lugar debemos hablar de América Latina ya que es el continente que ha estado a la vanguardia del movimiento abolicionista, aquí encontramos 15 Estados que han eliminado completamente la pena de

\footnotetext{
11. cfr., Por orden cronológico de acuerdo a la fecha de abolición de la pena de muerte para los delitos comunes: Israel, República de Fiyi, Brasil, Perú, El Salvador, Chile y Kazajistán.

12. cfr., Los últimos en incorporarse a esta lista han sido Madagascar, la República del Congo y Surinam, que en el año 2015 decidieron abolir la pena capital para todos los delitos.
} 
muerte ${ }^{13}$, y aunque la abolición no ha sido permanente en todos ellos, pues se han producido retrocesos debido a la inestabilidad política (Biglino \& Schabas,W, 2010), podemos ver como el antiguo compromiso abolicionista ha sobrevivido en el continente latinoamericano (Gomez de la torre, 1975).

\section{En SEgundo lugar, SE tiene QUe hablar de Europa, tanto oriental como occidental}

Por un lado, en Europa occidental actualmente encontramos un total de 28 Estados que han suprimido de sus legislaciones la pena capital ${ }^{14}$ siguiendo el pensamiento humanista europeo del siglo XVIII, que inspiró el movimiento abolicionista del continente. Sin embargo, cada país ha seguido métodos distintos hasta lograr la abolición definitiva de la pena de muerte, estos medios han estado marcados por la idiosincrasia propia de cada Estado. Por ejemplo, en la antigua República Federal Alemana, la última ejecución se produjo en 1949 y ese mismo año mediante una Ley Fundamental se eliminó completamente la pena de muerte; sin embargo, en Liechtenstein, se abolió la pena capital en 1987, pero tras una moratoria de más de 200 años, pues la última ejecución en este país se había producido en 1785.

Por otro lado, en Europa oriental el movimiento abolicionista llegó más tarde, cuando la democracia alcanzó casi la totalidad de Estados que se habían encontrado bajo la influencia soviética. Ahora existen en esta región 12 Estados de Europa del Este que han abolido definitivamente la pena de muerte ${ }^{15}$.

En tercer lugar, el continente de Oceanía también debe ubicarse en este grupo pues en él existen 10 Estados que de iure han eliminado la pena capital para todos los delitos y en todas las circunstancias ${ }^{16}$. En esta región el proceso abolicionista ha sido muy similar al de Europa occidental y ha estado muy influido por sus valores humanistas y utilitaristas.

Finalmente, en este grupo podemos añadir algunos de los Estados que formaban la antigua Unión de Repúblicas Socialistas Soviéticas (URSS), ya que a partir de 1980 se comenzó a extender por la zona el movimiento abolicionista, motivado, en gran parte, por los deseos de los nuevos Estados de integrarse en el Consejo de Europa y eventualmente en la Unión Europea.

\section{El marco JuRídico internacional de LA PENA DE MUERTE}

Este apartado se centra en la regulación que se ha desarrollado sobre la pena de muerte a nivel global en el ámbito de NNUU'17.

\footnotetext{
13. cfr., Estados abolicionistas de América Latina por orden de eliminación de la pena capital: Venezuela, Costa Rica, Ecuador, Uruguay, Colombia, Panamá, Honduras, República Dominicana, Nicaragua, Haití, Paraguay, Bolivia, Méjico, Argentina y Surinam.

14. cfr., Estados abolicionistas de Europa Occidental por orden de eliminación de la pena capital: San Marino, Islandia, Alemania, Mónaco, Austria, Ciudad del Vaticano, Suecia, Finlandia, Portugal, Dinamarca, Luxemburgo, Noruega, Holanda, Liechtenstein, Rumanía, Irlanda, Andorra, Eslovaquia, Suiza, Italia, España, Bélgica, Reino Unido, Malta, Chipre, Grecia, Turquía y Francia.

15. cfr., Estados abolicionistas de Europa Oriental por orden de eliminación de la pena capital: Alemania del Este (antigua República Democrática Alemana), Eslovenia, Hungría, República Checa, Croacia, Macedonia, Polonia, Bulgaria, Bosnia y Herzegovina, Serbia, Montenegro y Albania.

16. cfr., Estados abolicionistas de Oceanía por orden de eliminación de la pena capital: Tuvalu, Islas Salomón, República de Kiribati, República de Vanuatu, Australia, Micronesia, Nueva Zelanda, República de Palaos, Estado Independiente de Samoa y las Islas Cook.

17. cfr., Además de los instrumentos elaborados en el marco de Naciones Unidas, ha de subrayarse que el Derecho Penal Internacional también ofrece una interesante perspectiva para conocer cuál es la posición de la comunidad internacional ante la pena de muerte pero que no se abordará en este apartado dada la dimensión de la investigación En este sentido, por ejemplo, se debe destacar que la Corte Penal Internacional excluye la pena de muerte como sanción a imponer y determina que la sanción más grave aplicable a un condenado será la cadena perpetua (art.77 del Estatuto de Roma) aunque permite que los Estados que hayan ratificado el Estatuto de Roma pero mantengan vigente la pena capital en su legislación interna puedan continuar aplicándola dentro de su jurisdicción (art. 80 del Estatuto de Roma).
} 


\section{La pena de muerte y las Naciones Unidas}

Las NNUU han trabajado intensamente por la abolición de la pena de muerte desde su creación. La primera discusión sobre la pena capital se planteó ya en 1947 (Arroyo , Biglinio, \& Schabas, 2010) y desde entonces se han elaborado diversos instrumentos jurídicos que conforman el marco global de la pena de muerte, entre los que se debe destacar:

\section{a) Declaración Universal de Derechos Humanos}

El 10 de diciembre de 1948 la Asamblea General de NNUU (AG) aprobó la Declaración Universal de Derechos Humanos (DUDH), que lograba, en principio, un consenso prácticamente mundial sobre la eliminación de la pena de muerte. Sin embargo, la redacción final del artículo 3 de la DUDH, aunque declara literalmente: "Todo individuo tiene derecho a la vida (...)" no hace una referencia concreta a la pena capital como una negación de ese derecho a la vida, que por el contrario sí queda global y explícitamente reconocido. Esta laguna jurídica, redactada así intencionalmente, mostraba un consenso sobre el respeto al derecho a la vida, pero no reflejaba un acuerdo respecto a la pena de muerte, dejando desde entonces abierto un debate que todavía en la actualidad continúa siendo objeto de polémica (Arroyo , Biglinio, \& Schabas, 2010).

b) Pacto Internacional de Derechos civiles y políticos

Tuvieron que transcurrir cerca de dos décadas desde la proclamación y el reconocimiento del derecho a la vida en la DUDH hasta su reconocimiento en un instrumento legal de carácter vinculante (Salado Osuna, 1999): el Pacto Internacional de Derechos Civiles y Políticos (PIDCP) ${ }^{18}$. Actualmente el PIDCP ha sido ratificado por 155 Estados aproximadamente, adquiriendo por tanto sus principios una aceptación prácticamente universal (Schabas, 2008). Respecto al tema que nos ocupa, reconoce el derecho a la vida y aborda directamente el debate sobre la pena capital principalmente en su artículo 6.

En primer lugar, este artículo reconoce la prohibición de privar a una persona de su derecho a la vida "arbitrariamente". Para Salado Osuna este término significa que la vida es un derecho que admite excepciones, y aunque el PIDCP no las regule expresamente, reconoce más tarde la pena de muerte como una de estas excepciones (Salado Osuna, 1999). En segundo lugar, se determina que aquellos países que mantienen la pena de muerte, deberán aplicarla conforme a lo establecido por el artículo 6.2 PIDCP y únicamente frente a los culpables de los delitos más graves. (Schabas, 2008) En tercer lugar, los Estados partes que afronten el delito de genocidio mediante la imposición de la pena capital, deberán aplicarla cumpliendo, en todo momento, las disposiciones previstas en la Convención de NNUU para la Prevención y la Sanción del Delito de Genocidio de 1948.

Además, se establecen una serie de derechos que se deben conceder a los condenados a muerte y se prohíbe incondicionalmente la ejecución de aquellas personas que en el momento de cometer el delito capital sean menores de 18 años; $y$ de aquellas mujeres que en el momento de ejecutar la sanción se encuentren embarazadas, sin distinción de ningún plazo de gestación. Finalmente, el artículo 6 PIDCP añade un último párrafo con un carácter más bien programático 
que normativo, dirigido a impedir que un Estado Parte del presente Pacto invoque el art. 6 del mismo para aplazar o evitar la abolición de la pena capital. (Schabas, 2008)

\section{c) Segundo Protocolo Facultativo del PIDCP}

Después del camino abierto por la DUDH y el PIDCP, existían Estados que querían dar un paso más hacia la abolición de la pena de muerte, siguiendo la iniciativa de estos Estados abolicionistas, la Asamblea aprobó y proclamó el Segundo Protocolo Facultativo del PIDCP en 1989, que actualmente cuenta con 82 Estados Parte y 35 firmantes. Los Estados Parte de este protocolo adicional manifiestan su deseo de contraer formalmente un compromiso internacional para abolir la pena de muerte. Para ello, asumen mediante este protocolo, la labor de tomar todas las medidas que resulten necesarias para eliminar la pena capital de sus legislaciones internas y no ejecutar dentro de sus fronteras.

\section{d) Salvaguardias de 1984}

Con la finalidad de delimitar las ejecuciones sumarias conforme al art. 6 del PIDCP, la AG aprobó en el año 1984 las: “Salvaguardias para Garantizar la Protección de los Derechos de los Condenados a la Pena de Muerte"19, que son comúnmente conocidas como "Salvaguardias de 1984" y desarrollan el contenido del artículo 3 de la DUDH. “Las Salvaguardias manifiestan la aceptación de las ejecuciones en aquellos países que continúan aplicando la pena de muerte conforme a su legislación vigente. Sin embargo, estas ejecuciones sólo podrán llevarse a cabo cumpliendo los principios que disponen las Salvaguardias. Para ello, se establecen los derechos que deben reconocerse y respetarse a los condenados a pena de muerte por los Estados que no han abolido esta sanción. Estos derechos pueden resumirse mediante los siguientes conceptos conforme lo establece (Salado Osuna, 1999) y (Schabas, 2008) asi: :

- Sólo podrá imponerse la pena capital por los delitos más graves.

- No podrá aplicarse la pena de muerte de manera retroactiva.

- No podrán ser condenados a muerte los menores de 18 años ${ }^{20}$, mujeres embarazadas, o que hayan dado a luz recientemente, las personas mayores de 70 años o aquellas que sufran un retraso mental.

- Deben existir pruebas de cargo suficientes para emitir una sentencia de muerte.

- La pena de muerte sólo podrá ejecutarse cuando haya sido dictada en una sentencia definitiva, tras la celebración de un proceso judicial en el que se hayan respetado las garantías legales necesarias para considerarlo justo.

- Las personas condenadas a muerte tendrán derecho a apelar, a solicitar el indulto y la conmutación de la pena.

- $\quad$ No se ejecutará la pena capital cuando esté pendiente alguno los procedimientos enunciados en el anterior precepto.

- $\quad$ La pena capital debe ejecutarse causando el menor sufrimiento posible al condenado.

\section{Regulación de La pena de muerte en el ámbito europeo}

Los desastres provocados por la Segunda Guerra Mundial desencadenaron un cambio en la percepción de la pena de muerte por los Estados de Europa occidental. Se produjo una evolución

\footnotetext{
19. cfr., La Salvaguardias fueron aprobadas, en primer lugar, por el Comité de Prevención del Delito y de Control, posteriormente, por el Consejo Económico y Social en su resolución 1984/50, de 25 de mayo de 1984, y finalmente las aprobaron la AG y el Séptimo Congreso de las NNUU sobre Prevención del Delito y el Tratamiento del Delincuente, celebrado el Milán en 1985.

20cfr., En este sentido también se manifestó la Convención sobre los Derechos del Niño de 1989, que en su artículo 37 prohíbe la ejecución de aquellos delincuentes que al cometer el delito capital fuesen menores de 18 años.
} 
de la política penal europea bajo el principio de "no castigar menos, sino castigar mejor", como dijo Focault ${ }^{21}$, siguiendo las corrientes penales evolucionistas que afirmaban la incompatibilidad de un Derecho Penal retribucioncita con los ideales de una sociedad civilizada (Arroyo , Biglinio, \& Schabas, 2010).

En este contexto se creó el Consejo de Europa, una organización internacional integrada por 47 Estados europeos que tiene como objetivo principal proteger y defender la democracia, el Estado de derecho y los derechos humanos, civiles y políticos; ha liderado la lucha contra la pena de muerte en el continente europeo. Por otro lado, debe hacerse referencia al Tribunal Europeo de Derechos Humanos, que mediante su jurisprudencia ${ }^{22}$ ha contribuido a reforzar la vía abolicionista en el continente europeo.

a) Convenio Europeo para la Protección de los Derechos Humanos y de las Libertades Fundamentales

El Convenio Europeo para la Protección de los Derechos Humanos y de las Libertades Fundamentales (CEDH), fue firmado en Roma el 4 de noviembre de 1950 y son Estados Parte los 47 Estados que integran el Consejo de Europa. Se redactó con la finalidad de proteger los derechos humanos y las libertades fundamentales de las personas sometidas a la jurisdicción de los Estados miembros y está inspirado en la DUDH, a la que ya se ha hecho referencia anteriormente.

Centrándonos en el propio convenio, debemos detenernos en el art. 3 del mismo, el cual determina: "Nadie podrá ser sometido a tortura ni a penas o tratos inhumanos o degradantes", por lo que entendemos que la pena de muerte sería una sanción inaplicable por los Estados Parte en virtud del art. 3 del CEDH. No obstante, el art. 2, del mismo texto en su párrafo $1^{\circ}$ establece: “Nadie podrá ser privado de su vida intencionadamente, salvo en ejecución de una condena que imponga pena capital dictada por un tribunal al reo de un delito para el que la ley establece esa pena". Es decir, el CEDH prohíbe toda muerte que sea provocada de manera intencional, sin embargo, no prohíbe la pena capital ya que esta podrá imponerse por un tribunal cuando el reo haya cometido un delito para el que la ley (interna) establece esta pena. Teniendo en cuenta estos preceptos, si el derecho a la integridad física y moral protegido por el art. 3 del convenio, es un derecho absoluto, sería completamente incompatible la aplicación de la pena de muerte que admite el art. 2.1 del mismo texto, ya que la pena capital constituye la mayor vulneración posible de la integridad física, e incluso moral, y este bien jurídico está incondicionalmente protegido por el art. 3 del CEDH (Salado Osuna, 1999) ${ }^{23}$.

La Asamblea Parlamentaria abordó nuevamente el tema ${ }^{24}$ considerando que la pena de muerte permitida por el art. 2.1 era per se una violación de lo establecido en el art. 3 del CEDH y finalmente el Comité de Ministros, órgano legislador del Consejo de Europa, retomó la cuestión

\footnotetext{
21. cfr., Citado por YORKE, J. "La evolución del discurso de los derechos humanos del Consejo de Europa: la renuncia al derecho del soberano a imponer la pena de muerte". En (Arroyo, Biglinio, \& Schabas, 2010)

22. cfr., No obstante, la extensión de este trabajo impide abordar la jurisprudencia del Tribunal Europeo de Derechos Humanos. Vid. por ejemplo, el caso Öcalan vs. Turquía y el caso Soering. (Citados por YORKE, J. "La evolución del discurso de los derechos humanos del Consejo de Europa: la renuncia al derecho del soberano a imponer la pena de muerte". En (Arroyo, Biglinio, \& Schabas, 2010)

23. cfr., Por ello se ha señalado la contradicción interna en el texto del Convenio.

24. cfr., La Asamblea Parlamentaria del Consejo de Europa elaboró en 1980 el Informe 1980, la Recomendación 819 de 1980 y la Resolución 727 , para que los Estados miembros del Consejo de Europa eliminasen la pena de muerte de sus sistemas penales para los delitos cometidos en tiempos de paz. (YORKE, J. "La evolución del discurso de los derechos humanos del Consejo de Europa: la renuncia al derecho del soberano a imponer la pena de muerte". En ARROYO, L; BIGLINO, P; SCHABAS, W., Hacia la Abolición Universal de la pena capital, Tirant lo Blanch, Valencia, 2010).
} 
y comenzó la redacción de lo que llegó a ser el Protocolo núm. 6 al CEDH. (Arroyo , Biglinio, \& Schabas, 2010)

\section{Protocolo núm. 6 al CedH relativo a la abolición de la pena de muerte}

Fue elaborado en 1983 y es uno de los protocolos adicionales, pues se trata de un texto anexo al CEDH que pretende incrementar los derechos reconocidos por este, y cuya firma es libre para los Estados miembros del CEDH, lo cual permite flexibilidad, aunque genera diferencias entre los Estados que integran el Consejo de Europa.

El Protocolo núm. 6 al CEDH asume que a finales del siglo XX se ha producido una evolución penológica en la mayoría de Estados de Europa occidental a favor de la abolición de la pena de muerte, y siguiendo esta tendencia establece en su art. 1: "Queda abolida la pena de muerte. Nadie podrá ser condenado a tal pena ni ejecutado". Sin embargo, la polémica no termina aquí porque la abolición absoluta que enuncia el art. 1 del Protocolo núm. 6 no está libre de excepciones, ya que en el art. 2 del mismo se prevé una salvedad al reconocer: "Un Estado podrá prever en su legislación la pena de muerte por actos cometidos en tiempo de guerra o de peligro inminente de guerra". Pero el problema fundamental gira en torno a que se debe recordar que años atrás, se había iniciado la redacción del Protocolo núm. 6 para enmendar la discordancia existente entre los artículos 2.1 y 3 del CEDH, pero con el texto que finalmente había adoptado el Protocolo núm. 6 no se resolvía esta contradicción.

Según Wohlwend, Relatora del Comité de Asuntos Legales y Derechos Humanos, el Protocolo núm. 6 presentaba esencialmente 3 debilidades. En primer lugar, no abolía la pena de muerte pues la mantenía en tiempos de guerra o de una inminente amenaza de guerra; en segundo lugar, no establecía ningún obstáculo para el restablecimiento de la pena capital; y en tercer lugar, no enmendaba el art. 2.1 del CEDH. (Arroyo , Biglinio, \& Schabas, 2010) Ante esta situación finalmente se redactó el Protocolo núm. 13 para satisfacer los deseos de la Asamblea Parlamentaria del Consejo de Europa y lograr la enmienda del art. 2.1 del CEDH que dotase de armonía al texto.

b) Protocolo núm. 13 al CEDH relativo a la abolición de la pena de muerte en todas las circunstancias

Siguiendo las iniciativas de la Asamblea Parlamentaria para lograr la completa abolición de la pena de muerte en los Estados miembros del Consejo de Europa, se elaboró finalmente el Protocolo núm. 13 al CEDH de 2002, que es también uno de los denominados protocolos adicionales y actualmente cuenta con 45 Estados Parte. El Protocolo núm. 13 para lograr su finalidad de eliminar completamente la pena capital, manifiesta en su art. 1: "Queda abolida la pena de muerte. Nadie podrá ser condenado a dicha pena ni ejecutado".

Podemos observar que en los Protocolos núm. 6 y 13 al CEDH el enunciado del art. 1 es exactamente igual, la diferencia radica en los artículos que siguen al art. 1, pues al contrario que en el caso anterior, en el Protocolo núm. 13, los artículos 2 y 3 establecen la prohibición de realizar excepciones y reservas a lo dispuesto por el art. 1 del mismo. De manera que finalmente con la entrada en vigor del Protocolo núm. 13 al CEDH la pena de muerte quedó abolida, sin excepciones, en la mayor parte de Europa occidental. 


\section{Conclusiones}

Tras la elaboración de esta investigación podemos decir que el debate sobre el uso la pena de muerte es una cuestión profundamente relevante debido a que afecta todos los Estados puesto que, irremediablemente, en algún momento de su historia cada uno de ellos ha debido tomar una decisión respecto a la aplicación o abolición de la pena capital.

En primer lugar, los resultados sobre el estudio de los países retencionistas muestran que se trata del grupo minoritario, estos Estados se encuentran ubicados fundamentalmente en Oriente Medio, Asia, África y Norteamérica. De este modo, podemos resolver que generalmente es la situación política de los Estados retencionistas, la que crea la "necesidad" en éstos de recurrir a la pena de muerte como un instrumento para salvaguardar el orden público. Además, en este apartado hemos apreciado la urgencia de desarrollar nuevas líneas de investigación, centradas en la averiguación del uso de la pena capital en regiones como Corea del Norte y China, ya que el número de ejecuciones en estos países es un secreto de Estado y, a pesar de que no se conocen datos oficiales, se estima que estamos ante los mayores ejecutores del mundo.

En segundo lugar, las investigaciones realizadas sobre los países que han decidido eliminar la pena de muerte revelan que la tendencia imperante en el mundo es la abolicionista. No obstante, no todos los Estados abolicionistas se encuentran en la misma situación, debido a que el proceso abolicionista puede ser muy dilatado si se siguen sucesivamente cada una de sus etapas. De todos modos, es innegable que la culminación del abolicionismo se produce con la abolición de iure de la pena de muerte sin excepciones y el mayor número de Estados actualmente se encuentran en este punto.

Por otro lado, el estudio emprendido sobre el marco jurídico internacional que regula esta sanción, ha evidenciado que las numerosas implicaciones realizadas por organismos internacionales de gran relevancia como NNUU o el Consejo de Europa, han logrado desarrollar mecanismos legales en los que se regula sobre la pena capital como la DUDH, el PIDCP así como el CEDH y sus Protocolos 6 y 13. Mediante ellos se ha logrado que la tendencia imperante sea el abolicionismo. No obstante, junto con los Estados abolicionistas inciden todavía Estados retencionistas, de este modo, podemos observar que pese a los esfuerzos realizados por estos organismos internacionales, el debate respecto al uso de la pena de muerte realmente continúa abierto hoy día, en la actualidad, no existe un acuerdo global sobre la materia que vincule a todos los Estados.

Finalmente, se podría aportar una visión prospectiva sobre la materia, pero para ello deberíamos retornar en primer lugar a los albores de la historia, pues desde el origen de nuestras culturas la pena de muerte ha convivido en las distintas sociedades como un recurso legal, religioso o consuetudinario. Las razones y finalidades de su aplicación han sido muchas y muy diversas, pero resulta inexcusable que antiguamente existía una gran predisposición para hacer uso de la pena de muerte, tendencia que a lo largo de los siglos, también por diversos motivos de distinta naturaleza, ha comenzado a cambiar hasta el punto de invertir la balanza y que actualmente la inclinación preponderante sea el abolicionismo. Por todo ello, lo más sensato es considerar que de cara al futuro, cada vez más países formarán parte del bloque abolicionista, pero al mismo tiempo debemos entender que mientras una parte de estos Estados retencionistas mantengan 
abiertos conflictos internos de carácter bélico, político o religioso, es difícil que al menos estos países ejecutores inicien el camino abolicionista.

\section{Referencias bibliográficas}

Amnistia Internacional,. (2015- 2016). Amnistía Internacional. Recuperado de Amnistía Internacional: https://www.amnesty.org/es/latest/research/2016/02/annual-report-201516/)

Hood, R., \& Hoyle, C. (2017). La pena de muerte. Una perspectiva mundial. Valencia : Tirant lo Blanch.

Amnistía Internacional. (27 de octubre de 1995). Amnistía Internacional;: Recuperado el 15 de Agosto de 2019, de Amnistía Internacional;: https://www.amnesty.org/download/Documents/172000/act500061995es.pdf

Arroyo , L., Biglinio, P., \& Schabas, W. (2010). Hacia la abolicion de la pena capital. Valencia: Tirant lo Blanch.

Barbero, Santos, M. (2013). Clasicos españoles sobre la pena de muerte. Ciudad Rel: Universidad Castilla de la Mancha.

Biglino, P., \& Schabas,W. (2010). Hacia la Abolición Universal de la pena capital. Valencia: Tirant lo Blanch.

Gallego, j. A. (2005). Los argumentos esclavistas y los argumentos. Revista del CESLA, 63-108.

Gomez de la torre, B. (1975). “La pena de muerte en el actual derecho penal iberoamericano". Valladolid: Universidad de Salamanca.

Salado Osuna, A. (1999). La pena de muerte en el derecho internacional: Una exepcion al derecho a la vida. Madrid: Tecnos.

Schabas, W. (2008). Las Naciones Unidas y la abolicion de la pena de muerte. Centro irlandes de derechos humanos - Universidad Nacional de Galway Irlanda, 25-68.

Unidas, N., \& Naciones Unidas . (1 de junio de 2013). La Onu y los derechos humanos. Recuperado el 15-08-2019 de agosto de 2019, de La Onu y los derechos humanos: https:// www.un.org/es/rights/overview/hrcouncil.shtml 


\section{Anexos}

\section{Lista de países Retencionistas}

La tabla muestra los países activamente retencionistas que mantienen la pena de muerte a fecha 31 de diciembre de 2015, y han realizado al menos una ejecución en los últimos 10 años sin haber anunciado una moratoria.

\begin{tabular}{|c|c|}
\hline País/estado o territorio & FECHA DE LA ÚLTIMA EJECUCIÓN \\
\hline Afganistán & 2013 \\
\hline Arabia Saudí & 2014 \\
\hline Autoridad Palestina & 2013 \\
\hline Bahréin & 2010 \\
\hline Bangladesh & 2015 \\
\hline Bielorrusia & 2014 \\
\hline Botsuana & 2013 \\
\hline China & 2015 \\
\hline Chad & 2015 \\
\hline Corea del Norte & 2015 \\
\hline Egipto & 2011 \\
\hline Emiratos Árabes Unidos & 2014 \\
\hline Estados Unidos de América & 2014 \\
\hline Etiopía & 2007 \\
\hline Gambia & 2012 \\
\hline Guinea Ecuatorial & 2010 \\
\hline India & 2015 \\
\hline Indonesia & 2015 \\
\hline Irak & 2014 \\
\hline Irán & 2014 \\
\hline Japón & 2014 \\
\hline Jordania & 2006 \\
\hline Kuwait & 2013 \\
\hline Libia & 2010 \\
\hline Malasia & 2013 \\
\hline Pakistán & 2012 \\
\hline San Cristóbal y Nieves & 2008 \\
\hline Singapur & 2011 \\
\hline Siria & 2012 \\
\hline
\end{tabular}




\begin{tabular}{ll} 
Somalia & 2014 \\
Sudán & 2013 \\
Sudán del Sur & 2015 \\
Tailandia & 2009 \\
Taiwán & 2014 \\
Uganda & 2006 \\
Vietnam & 2013 \\
Yemen & 2013 \\
Zimbabue & 2005 \\
\hline
\end{tabular}

Tabla 1. tomada de ( Hood \& Hoyle, 2017)

\section{LISTA DE PAÍSES ABOLICIONISTAS DE FACTO}

La tabla muestra los países que mantienen la pena de muerte en su legislación, pero pueden ser considerados abolicionistas de facto porque no han realizado ejecuciones en los últimos 10 años o actualmente mantienen una moratoria oficial a fecha 31 de diciembre de 2015.

\section{País/Estado o territorio}

Fecha de la última ejecución

\begin{tabular}{lr}
\hline Antigua y barbuda & 1991 \\
Argelia & 1993 \\
Bahamas & 2000 \\
Barbados & 1984 \\
Belice & 1985 \\
Brunei & 1957 \\
Burkina Faso & 1988 \\
Camerún & 1997 \\
Comoras & 1997 \\
Corea del Sur & 1997 \\
Cuba & 2003 \\
Dominica & 1986 \\
Eritrea & 1989 \\
Ghana & 1993 \\
Granada & 1978 \\
Guatemala & 2000 \\
Guayana & 1996
\end{tabular}


Guinea

2001

Jamaica

1988

Kenia

1987

Laos

1989

Lesoto

1995

Líbano

2004

Liberia

2000

Malawi

1992

Maldivas

1952

Mali

1980

Marruecos

1993

Mauritania

1989

Myanmar

1989

Nauru

1968

Níger

1976

Papúa Nueva Guinea

1954

Qatar

2003

República Centroafricana

1981

República del Congo

2003

Rusia

1996

San Vicente y las Granadinas

1995

Santa Lucía

1995

Sierra Leona

1998

Sri Lanka

1976

Suazilandia

1983

Tayikistán

2004

Tanzania 1994

Tonga

1982 
Tabla 2. tomada de ( Hood \& Hoyle, 2017)

\section{LISTA DE PAÍSES PARCIALMENTE ABOLICIONISTAS DE IURE}

La tabla muestra los países que a fecha 31 de diciembre de 2015 han abolido la pena de muerte, pero solo para los delitos comunes.

\begin{tabular}{ccc}
\hline $\begin{array}{c}\text { País/estado o te- } \\
\text { RRItorio }\end{array}$ & $\begin{array}{c}\text { Fecha de abolición } \\
\text { Para delitos comunes }\end{array}$ & $\begin{array}{c}\text { Fecha de La Última } \\
\text { EJecución }\end{array}$ \\
\hline Brasil & 1979 & 1855 \\
Chile & 2001 & 1985 \\
El Salvador & 1983 & 1973 \\
Israel & 1954 & 1962 \\
Kazajistán & 2007 & 2003 \\
Perú & 1979 & 1979 \\
\hline
\end{tabular}

Tabla 3. tomada de ( Hood \& Hoyle, 2017)

\section{Lista de PAÍSES TOTALMENTE ABOLICIONISTAS DE IURE}

La tabla muestra los países que a fecha 31 de diciembre de 2015 han abolido la pena de muerte para todos los delitos, tanto en tiempos de guerra como en tiempos de paz.

\begin{tabular}{|c|c|c|c|}
\hline País/estado o terRItorio & $\begin{array}{l}\text { FECHA DE ABOLICIÓN } \\
\text { PARA DELITOS COMUNES }\end{array}$ & $\begin{array}{l}\text { FECHA DE ABOLICIÓN } \\
\text { PARA TOdO TIPO DE CRí- } \\
\text { MENES }\end{array}$ & $\begin{array}{c}\text { FECHA DE LA ÚLTIMA } \\
\text { EJECUCIÓN }\end{array}$ \\
\hline Albania & 2000 & 2007 & 1995 \\
\hline Alemania & - & 1949 & 1948 \\
\hline Antigua RDA & - & 1987 & 1981 \\
\hline Andorra & - & 1990 & 1943 \\
\hline Angola & - & 1992 & no conocida (n.c.) \\
\hline Argentina & 1984 & 2008 & 1916 \\
\hline Armenia & - & 2003 & 1991 \\
\hline Australia & 1984 & 1985 & 1967 \\
\hline Austria & 1950 & 1968 & 1950 \\
\hline
\end{tabular}




\begin{tabular}{|c|c|c|c|}
\hline Azerbaiyán & - & 1998 & 1993 \\
\hline Bélgica & - & 1996 & 1950 \\
\hline Benín & - & 2012 & 1987 \\
\hline Bolivia & 1995 & 1997 & 1974 \\
\hline Bosnia y Herzegovina & 1997 & 2001 & 1991 \\
\hline Bulgaria & - & 1998 & 1989 \\
\hline Burundi & - & 2009 & 1999 \\
\hline Bután & - & 2004 & 1964 \\
\hline Cabo Verde & - & 1981 & 1835 \\
\hline Camboya & - & 1989 & 1989 \\
\hline Canadá & 1976 & 1998 & 1962 \\
\hline Chipre & 1983 & 2002 & 1962 \\
\hline Ciudad del Vaticano & - & 1969 & n.c. \\
\hline Colombia & - & 1910 & 1909 \\
\hline Costa de Marfil & - & 2000 & 1960 \\
\hline Costa Rica & - & 1877 & 1859 \\
\hline Croacia & - & 1991 & 1987 \\
\hline Dinamarca & 1933 & 1978 & 1950 \\
\hline Ecuador & - & 1906 & 1884 \\
\hline Eslovaquia & - & 1990 & 1989 \\
\hline Eslovenia & - & 1989 & 1957 \\
\hline España & 1978 & 1995 & 1975 \\
\hline Estonia & - & 1998 & 1991 \\
\hline Filipinas & - & 2006 & 2000 \\
\hline Finlandia & 1949 & 1972 & 1944 \\
\hline Fiyi & 1979 & 2015 & 1964 \\
\hline Francia & - & 1981 & 1977 \\
\hline Gabón & - & 2000 & 1989 \\
\hline Georgia & - & 1997 & 1994 \\
\hline Grecia & 1993 & 2004 & 1972 \\
\hline Guinea -Bissau & - & 1993 & 1986 \\
\hline Haití & - & 1987 & 1972 \\
\hline Holanda & 1870 & 1982 & 1952 \\
\hline Honduras & - & 1956 & 1940 \\
\hline Hungría & - & 1990 & 1988 \\
\hline Irlanda & - & 1990 & 1954 \\
\hline Islandia & - & 1928 & 1830 \\
\hline
\end{tabular}




\begin{tabular}{|c|c|c|c|}
\hline Islas Cook & 1965 & 2007 & n.c. \\
\hline Islas Salomón & 1966 & 1978 & 1966 \\
\hline Italia & 1947 & 1994 & 1947 \\
\hline Kirguizistán & - & 2007 & 1998 \\
\hline Kiribati & - & 1979 & 1979 \\
\hline Letonia & 1999 & 2012 & 1996 \\
\hline Liechtenstein & - & 1987 & 1785 \\
\hline Lituania & - & 1998 & 1995 \\
\hline Luxemburgo & - & 1979 & 1949 \\
\hline Macedonia & - & 1991 & 1989 \\
\hline Madagascar & - & 2015 & 1958 \\
\hline Malta & 1971 & 2000 & 1943 \\
\hline Mauricio & - & 1995 & 1987 \\
\hline Méjico & - & 2005 & 1937 \\
\hline Micronesia & - & 1986 & 1986 \\
\hline Moldavia & - & 1995 & 1989 \\
\hline Mónaco & - & 1962 & 1847 \\
\hline Mongolia & - & 2012 & 2008 \\
\hline Montenegro & - & 2002 & 1989 \\
\hline Mozambique & - & 1990 & 1986 \\
\hline Namibia & - & 1990 & 1988 \\
\hline Nepal & 1990 & 1997 & 1979 \\
\hline Nicaragua & - & 1979 & 1930 \\
\hline Noruega & 1905 & 1979 & 1948 \\
\hline Nueva Zelanda & 1961 & 1989 & 1957 \\
\hline Palau & - & 1994 & 1994 \\
\hline Panamá & - & 1922 & 1903 \\
\hline Paraguay & - & 1992 & 1928 \\
\hline Polonia & - & 1997 & 1988 \\
\hline Portugal & 1867 & 1976 & 1849 \\
\hline Reino Unido & 1965 & 1998 & 1964 \\
\hline República Checa & - & 1990 & 1989 \\
\hline República del Congo & - & 2015 & 2003 \\
\hline República Dominicana & - & 1966 & 1966 \\
\hline Ruanda & - & 2007 & 1998 \\
\hline Rumanía & - & 1989 & 1989 \\
\hline Samoa & - & 2004 & 1962 \\
\hline
\end{tabular}


San Marino

Santo Tomé y Príncipe

Senegal

Serbia

Seychelles

Sudáfrica

Suecia

Suiza

Surinam

Timor Oriental

Togo

Turkmenistán

Turquía

Tuvalu

Ucrania

Uruguay

Uzbekistán

vanuatu

Venezuela

Yibut
1848

1865

1990

2004

2002

1993

1997

1972

1992

2015

1999

2008

1999

2004

1976

1999

1907

2008

1980

1863

1995

Tabla 4. tomada de ( Hood \& Hoyle, 2017)
1468

1975

1967

1989

1976

1989

1910

1944

1982

1999

1978

1997

1984

1976

1997

n.c.

2006

1980

1830

1977 